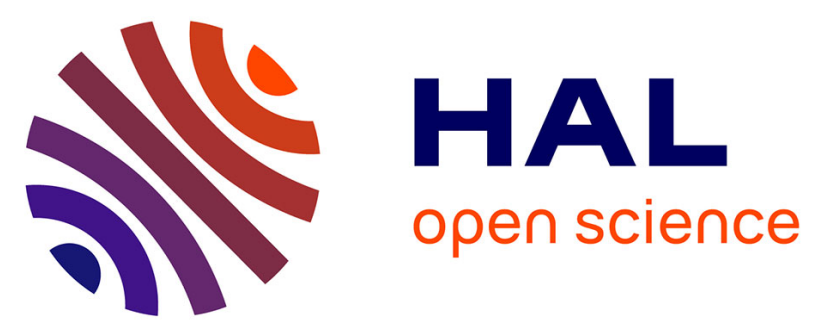

\title{
Laccase/HBT and laccase-CBM/HBT treatment of softwood kraft pulp: impact on pulp bleachability and physical properties
}

Holly Ravalason, Frédérique Bertaud, Isabelle Gimbert, Valérie Meyer, Katia Ruel, Jean-Paul Joseleau, Sacha Grisel, Caroline Olive-Lauge, Jean-Claude Sigoillot, Michel Petit-Conil

\section{To cite this version:}

Holly Ravalason, Frédérique Bertaud, Isabelle Gimbert, Valérie Meyer, Katia Ruel, et al.. Laccase/HBT and laccase-CBM/HBT treatment of softwood kraft pulp: impact on pulp bleachability and physical properties. Bioresource Technology, 2012, 121, pp.68-75. 10.1016/j.biortech.2012.06.077 . hal-01268169

\section{HAL Id: hal-01268169 \\ https://hal.science/hal-01268169}

Submitted on 29 May 2020

HAL is a multi-disciplinary open access archive for the deposit and dissemination of scientific research documents, whether they are published or not. The documents may come from teaching and research institutions in France or abroad, or from public or private research centers.
L'archive ouverte pluridisciplinaire HAL, est destinée au dépôt et à la diffusion de documents scientifiques de niveau recherche, publiés ou non, émanant des établissements d'enseignement et de recherche français ou étrangers, des laboratoires publics ou privés. 


\title{
Laccase/HBT and laccase-CBM/HBT treatment of softwood kraft pulp: Impact on pulp bleachability and physical properties
}

\author{
Holy Ravalason a,b,c,*, Frédérique Bertaud ${ }^{c}$, Isabelle Herpoël-Gimbert a,b Valérie Meyer $^{c}$, Katia Ruel ${ }^{\mathrm{d}}$, \\ Jean-Paul Joseleau ${ }^{\mathrm{d}}$, Sacha Grisel ${ }^{\mathrm{a}, \mathrm{b}}$, Caroline Olivé ${ }^{\mathrm{a}, \mathrm{b}}$, Jean-Claude Sigoillot ${ }^{\mathrm{a}, \mathrm{b}}$, Michel Petit-Conil ${ }^{\mathrm{c}}$ \\ a INRA, UMR 1163 BCF, 13288 Marseille, France \\ ${ }^{\mathrm{b}}$ Aix-Marseille Univ, UMR 1163 BCF, 13288 Marseille, France \\ ${ }^{\mathrm{c}}$ Centre Technique du Papier, Domaine Universitaire, B.P. 251, 38044 Grenoble Cedex 9, France \\ ${ }^{\mathrm{d}}$ Centre de Recherches sur les Macromolécules Végétales (CERMAV), CNRS UPR 5301, BP 53, 38041 Grenoble Cedex 9, France
}

Keywords:

Laccase

CBM

Biobleaching

Softwood kraft pulp

Chlorine dioxide

\begin{abstract}
A B S T R A C T
Pycnoporus cinnabarinus laccase and a chimeric laccase-CBM were applied in softwood kraft pulp biobleaching in the presence of 1-hydroxybenzotriazole (HBT). The presence of CBM could enhance the laccase biobleaching potential as a decrease in the enzymatic charge and chlorine dioxide consumption, as well as an increase in pulp brightness were observed. Laccase/HBT treatment could be improved by increasing oxygen pressure from 1 to 3 bar and pulp consistency from $5 \%$ to $10 \%$. Conversely, under the same conditions, no improvement of laccase-CBM/HBT treatment was observed, indicating a different behavior of both systems. However, laccase-CBM/HBT treatment led to a better preservation of pulp properties. This effect was probably due to fiber surface modifications involving the action of the CBM. Transmission electron microscopy examination of pulp fibers indicated a retention of laccase-CBM inside the pulp fibers due to CBM binding and an increased external microfibrillation of the fibers due to enzymatic treatments.
\end{abstract}

\section{Introduction}

Bleached kraft pulp production is a dominant process contributing to more than $50 \%$ of the global pulp production. Traditionally, bleaching was performed using chlorine until it was shown that chlorine bleaching could lead to the production of halogenated organic compounds, measured as adsorbable organic halides (AOX), known to be particularly toxic substances (Muna and Sreekrishnan, 2001). Therefore, due to environmental concerns, pulp mills have

* Corresponding author at: INRA, UMR 1163 Biotechnologie des Champignons Filamenteux, Case 925, 163 Avenue de Luminy, 13288 Marseille Cedex 09, France. Tel.: +33 4918286 00; fax: +33491828601.

E-mail address: holy.ravalason@gmail.com (H. Ravalason). gradually eliminated chlorine from bleaching sequences. Nowadays, in most bleaching processes, chlorine dioxide is used as a substitute for chlorine, in elemental chlorine free (ECF) bleaching sequences, and demand for the use of non-chlorine based bleaching agents, such as oxygen, ozone or hydrogen peroxide, has increased. New technologies for pulp processing, such as enzyme-based pulp treatments, have also been developed to further decrease the environmental impact of pulp bleaching and the production costs. Indeed, some pulp mills have already included a hemicellulase stage, such as a xylanase stage, in their bleaching sequence (Beg et al., 2001). It was shown that xylanase pre-treatment of pulp could lead to a significant decrease in bleaching chemical consumption, by removing hemicelluloses from pulp, thus enhancing lignin accessibility to the bleaching agents. However, as the xylanase 
action does not directly target lignin, its potential in pulp biobleaching is limited. The use of lignin degrading enzymes, as efficient delignification agents, has therefore been investigated. In particular, laccases were shown to have a great potential for pulp delignification. Laccases (EC 1.10.3.2) are multicopper oxidases able to catalyze the oxidation of various phenolic compounds with the concomitant reduction of oxygen to water. Laccases are only able to directly oxidize phenolic lignin moieties. However, lignin degradation can be extended to the non-phenolic lignin units in the presence of a low molecular weight compound, acting as a redox mediator (Bourbonnais and Paice, 1990). Laccase/mediator systems (LMS) have been investigated in numerous studies for pulp delignification. Pycnoporus cinnabarinus laccase was shown to be particularly efficient for this kind of application (Herpoël et al., 2002; Sigoillot et al., 2004; Ibarra et al., 2006b). In a previous study, the fusion of a family 1 carbohydrate-binding-module (CBM), referring to the CAZy database (Cantarel et al., 2008; http://www.cazy.org), to the $P$. cinnabarinus laccase was shown to greatly improve the biobleaching potential of the enzyme (Ravalason et al., 2009). It was suggested that conferring a binding capability to the laccase could promote enzyme and substrate proximity, leading to an enhancement of laccase efficiency. Here, the impact of $P$. cinnabarinus laccase and laccase-CBM on softwood kraft pulp treatment, in the presence of 1-hydroxybenzotriazole (HBT) was further investigated. Pulp bleachability following the enzymatic treatments, as well as physical properties of the bleached pulp, were also analyzed. The interaction between the enzymes and the fibers and the resulting ultrastructural modifications of the pulp fibers were observed by transmission electron microscopy (TEM).

\section{Methods}

\subsection{Chemicals and enzymes}

2,2'-Azino-bis-3-ethylbenzthiazoline-6-sulphonate (ABTS) and 1-hydroxybenzotriazole (HBT) were purchased from Sigma-Aldrich (Lyon, France). P. cinnabarinus laccase was obtained from cultures of the monokaryotic strain ss3, now deposited as BRFM137 (Banque de Ressources Fongiques, Marseille, France), in 250-ml flasks, according to Herpoël et al. (2000). Laccase-CBM was obtained from cultures of an Aspergillus niger recombinant strain (Ravalason et al., 2009). Cultures were performed in 250-ml flasks according to Record et al. (2002). Laccase activity was measured by monitoring $\mathrm{A}_{420}\left(\varepsilon_{420}=36 \mathrm{mM}^{-1} \mathrm{~cm}^{-1}\right)$ with respect to the rate of oxidation of $500 \mu \mathrm{M}$ ABTS in sodium tartrate buffer $(50 \mathrm{mM}$, $\mathrm{pH} 4.0$ ) at $30^{\circ} \mathrm{C}$. Activities were expressed in international units (IU), 1 unit being defined as the amount of laccase that oxidizes $1 \mu \mathrm{mol}$ of substrate per min. The experiments were performed in triplicate and the standard deviation was lower than $10 \%$ of the average value.

\subsection{Enzymatic treatment of softwood kraft pulp}

A mixed softwood kraft pulp (kappa number: 22.7 and brightness: $29.9 \%$ ISO) was provided by Fibre Excellence's Tarascon mill (France).

\subsubsection{Laccase-CBM binding to the pulp}

Laccase-CBM was bound to the pulp by mixing $1400 \mathrm{U}$ of enzyme with $50 \mathrm{~g}$ (dry weight) of pulp for $2 \mathrm{~h}$ at $45^{\circ} \mathrm{C}$ in a water bath. The pulp consistency was adjusted to $5 \%$ using sodium acetate buffer ( $50 \mathrm{mM}, \mathrm{pH}$ 5.0). After incubation, the supernatant was separated from the pulp by filtration for residual laccase activity measurement. The fraction of enzyme bound to the substrate was calculated by subtracting the residual activity from the activity of
laccase-CBM incubated under the same conditions but without substrate. Under those conditions $5 \mathrm{U}$ of laccase-CBM were bound per gram of pulp (dry weight). After the binding step the pulp was thoroughly washed with water to remove the unbound fraction. As a control, pulp was treated under the same conditions with P. cinnabarinus laccase.

\subsubsection{Laccase/HBT and Laccase-CBM/HBT treatments}

Laccase/mediator system (LMS) treatments were further carried out in a 4 -L rotating laboratory pressure reactor. $1.5 \%$ odp HBT was added to $50 \mathrm{~g}$ (dry weight) of pulp pre-treated with laccase or laccase-CBM. For the laccase/HBT treatment, $20 \mathrm{U}$ of laccase were further added per gram of pulp. The pulp consistency was adjusted to $5 \%$ or $10 \%$ using sodium acetate buffer $(50 \mathrm{mM}, \mathrm{pH} 4.0)$. The reactor was filled with oxygen to a pressure of 1 or 3 bar and the temperature was adjusted to $45^{\circ} \mathrm{C}$. After $3 \mathrm{~h}$ treatment, the pulp was thoroughly washed with water to stop the reaction. An abiotic control experiment was performed under the same conditions in the absence of enzyme and mediator (LMS abiotic control).

\subsection{ECF bleaching of pulp}

Subsequently to the enzymatic treatments, the pulps were submitted to an alkaline extraction stage (E) at 10\% pulp consistency, using $1.5 \%$ odp $\mathrm{NaOH}$ at $70{ }^{\circ} \mathrm{C}$ for $1 \mathrm{~h}$.

The pulps were further subjected to a conventional ECF bleaching sequence as $\mathrm{D}_{0} \mathrm{E}_{1} \mathrm{D}_{1} \mathrm{E}_{2} \mathrm{D}_{2}$ (D: chlorine dioxide stage and $\mathrm{E}$ : alkaline extraction stage). The bleaching stages were carried out in sealed polyethylene bags placed in water baths maintained at the required temperature. Chemical charges (expressed as\% of dry weight of pulp) were as follows: for the $\mathrm{D}_{0}$ stage, the $\mathrm{ClO}_{2}$ charge was calculated on the basis of the kappa number of the pulp using the following relationship: $\% \mathrm{ClO}_{2}=($ kappa factor $) \times($ kappa number)/2.63. Two kappa factor values $(0.18$ and 0.21$)$ were applied for each pulp. The $\mathrm{ClO}_{2}$ charge applied in the $\mathrm{D}_{1}$ stage was half of the $\mathrm{D}_{0}$ stage charge. $0.3 \% \mathrm{ClO}_{2}$ was applied in the $\mathrm{D}_{2}$ stage charge. The $\mathrm{NaOH}$ charges were $1.5 \%$ in $\mathrm{E}_{1}$ and $0.8 \%$ in $\mathrm{E}_{2}$. The bleaching stages were performed at $10 \%$ consistency and $70{ }^{\circ} \mathrm{C}$, except for the $\mathrm{D}_{0}$ stage which was carried out at $55^{\circ} \mathrm{C}$. The duration was $1 \mathrm{~h}$ for the $D_{0}$ and $E$ stages and $2 \mathrm{~h}$ for the $D_{1}$ and $D_{2}$ stages. Pulp bleachability was compared to the initial pulp submitted to the same bleaching sequence without the enzymatic treatment step (ECF bleaching control).

\subsection{Analysis of pulp properties}

Pulp kappa number was determined according to standard ISO 302:1981.

Pulp brightness was evaluated according to standard ISO 2470:1999.

Residual amounts of $\mathrm{ClO}_{2}$ were measured by titration with $0.1 \mathrm{~N}$ sodium thiosulfate.

Pulp color was measured according to international standard ISO 5631:2000. The measurements were performed in quadriplate and the standard deviation was lower than $5 \%$ of the average value. Results were expressed in the three-dimensional CIELab color system $\left(L^{*}, a^{*}, b^{*}\right) . L^{*}$ corresponds to lightness (black/white coordinate), $a^{*}$ to the green/red coordinate and $b^{*}$ to the blue/yellow coordinate. Color difference, taking the unbleached kraft pulp as a reference, was calculated according to the following formula (Ohno, 2000):

$\Delta E_{a b}^{*}=\left[\left(\Delta L^{*}\right)^{2}+\left(\Delta a^{*}\right)^{2}+\left(\Delta b^{*}\right)^{2}\right]^{1 / 2}$

Intrinsic viscosity was determined according to standard ISO 5351-1:1981. 
Bleached pulp fiber morphology was measured using a MorFi LB-01 Fiber Analyzer (Techpap, France), on $0.3 \mathrm{~g}$ (dry weight) of pulp. Analyses were performed in duplicate.

Bleached pulp physical properties were measured according to the following Tappi standards: T404 cm92 (tensile index) and T496 cm85 (tear index), on Rapid-Köthen handsheets manufactured according to ISO 5269-2:2004 standard.

\subsection{Transmission electron microscopy}

Pulp samples were fixed by two methods, depending on the kind of analysis subsequently performed.

To visualize laccase and laccase-CBM by immunolabeling, pulp samples were taken at the end of the enzymatic treatments, washed with distilled water and fixed in a freshly prepared mixture of $0.2 \%$ glutaraldehyde $(\mathrm{v} / \mathrm{v}), 2 \%$ paraformaldehyde $(\mathrm{w} / \mathrm{v})$ in $0.05 \mathrm{M}$ phosphate buffer ( $\mathrm{pH} 7-7.2$ ), for $2 \mathrm{~h}$ at room temperature and overnight at $4{ }^{\circ} \mathrm{C}$. For lignin and micromorphological analysis, samples were taken at the end of the first alkaline extraction stage and fixed with $\mathrm{KMnO}_{4} 2.5 \%(\mathrm{w} / \mathrm{v}$ ) in water during $1.5 \mathrm{~h}$ (Kerr and Goring, 1975).

All the samples were further submitted to dehydration in a series of aqueous solutions of increasing ethanol concentration. Progressive infiltration with LR White resin (Electron Microscopy Sciences, Hatfield, USA) was carried out by serial incubation in ethanolic solutions of increasing LR White resin concentration followed by several incubations in 100\% LR White. The pulp samples were then embedded in gelatine capsules and the resin allowed to polymerize for $24 \mathrm{~h}$ at $50^{\circ} \mathrm{C}$. Ultrathin sections $(50 \mathrm{~nm}$ thickness) were prepared and either transferred on copper-grids for direct examination after $\mathrm{KMnO}_{4}$ staining, or collected on plastic rings for immunolabeling. For the detection of laccase and laccaseCBM, the sections were floated on several dilutions of specific antibodies raised against $P$. cinnabarinus laccase (Record et al., 2002) in $10 \mathrm{mM}$ Tris buffered saline $(500 \mathrm{mM} \mathrm{NaCl})$ to determine the optimal ratio of labeling and background (Ruel et al., 1994). The secondary marker was Auroprobe EM protein A conjugated with $5 \mathrm{~nm}$ colloidal gold (BB International, Cardiff, UK). The gold particles were further enhanced using a silver enhancing kit (Amersham Bioscience, Buckinghamshire, UK). Finally, the thin-sections were transferred on copper-grids and post-stained with $2.5 \%$ aqueous uranyl acetate. To verify the specificity of the antibodies and the method used, control pulp (LMS abiotic control) was treated under the same conditions. All the samples were further examined with a transmission electron microscope (Philips CM 200-Cryo) at an accelerating voltage of $80 \mathrm{kV}$ and pictures taken on 4489 Kodak film plates.

\section{Results and discussion}

\subsection{Laccase/HBT and laccase-CBM/HBT biobleaching of softwood kraft pulp}

In a previous study, it was shown that the fusion of a CBM to the $P$. cinnabarinus laccase could greatly enhance the delignification potential of the enzyme and led to a decrease in the enzymatic charge required for efficient softwood kraft pulp biobleaching (Ravalason et al., 2009). Indeed, compared to a laccase/HBT treatment with $20 \mathrm{U}$ of enzyme per gram of pulp and 3\% HBT, laccase-CBM/HBT treatment with $5 \mathrm{U} / \mathrm{g}$ of laccase-CBM led to an increase in pulp brightness after a DEDED bleaching sequence and a decrease in $\mathrm{ClO}_{2}$ consumption.

Here, laccase/HBT and laccase-CBM/HBT treatments of softwood kraft pulp were performed under the same conditions but HBT charge was decreased to $1.5 \%$. Compared to the unbleached pulp, a similar decrease in kappa number, of around $15 \%$, was measured after both enzymatic treatments and an alkaline extraction stage (Fig. 1A). The decrease in pulp kappa number was similar to that observed using a 3\% HBT charge (Ravalason et al., 2009). An ECF bleaching sequence was further applied to the pulps, and bleaching responses were evaluated by measuring the final brightness reached and the $\mathrm{ClO}_{2}$ consumed for each pulp. Pulp bleachability was defined as the amount of $\mathrm{ClO}_{2}$ consumed to obtain a target brightness (Fatehi et al., 2009). To allow comparison, two $\mathrm{ClO}_{2}$ charges, adjusted to pulp kappa numbers and expressed as kappa factors, were applied to the pulps. Final brightness levels, by applying an initial kappa factor of 0.21 , were around $85 \%$ ISO for the ECF bleaching control, the LMS abiotic control and the laccase/HBT treated pulp (Fig. 1B). The final brightness was enhanced after the laccase-CBM/HBT treatment and reached a value of 85.6 and $86.5 \%$ ISO for initial kappa factors of 0.18 and 0.21 , respectively. The laccase-CBM/HBT treatment also led to a decrease in chlorine dioxide consumption. Indeed, for a targeted $85 \%$ ISO brightness, $\mathrm{ClO}_{2}$ savings of $4.2 \mathrm{~kg} / \mathrm{T}$ of pulp and $8.5 \mathrm{~kg} / \mathrm{T}$ of pulp were calculated for the laccase/HBT and laccase-CBM/HBT treated pulps, respectively. These values were calculated according to the
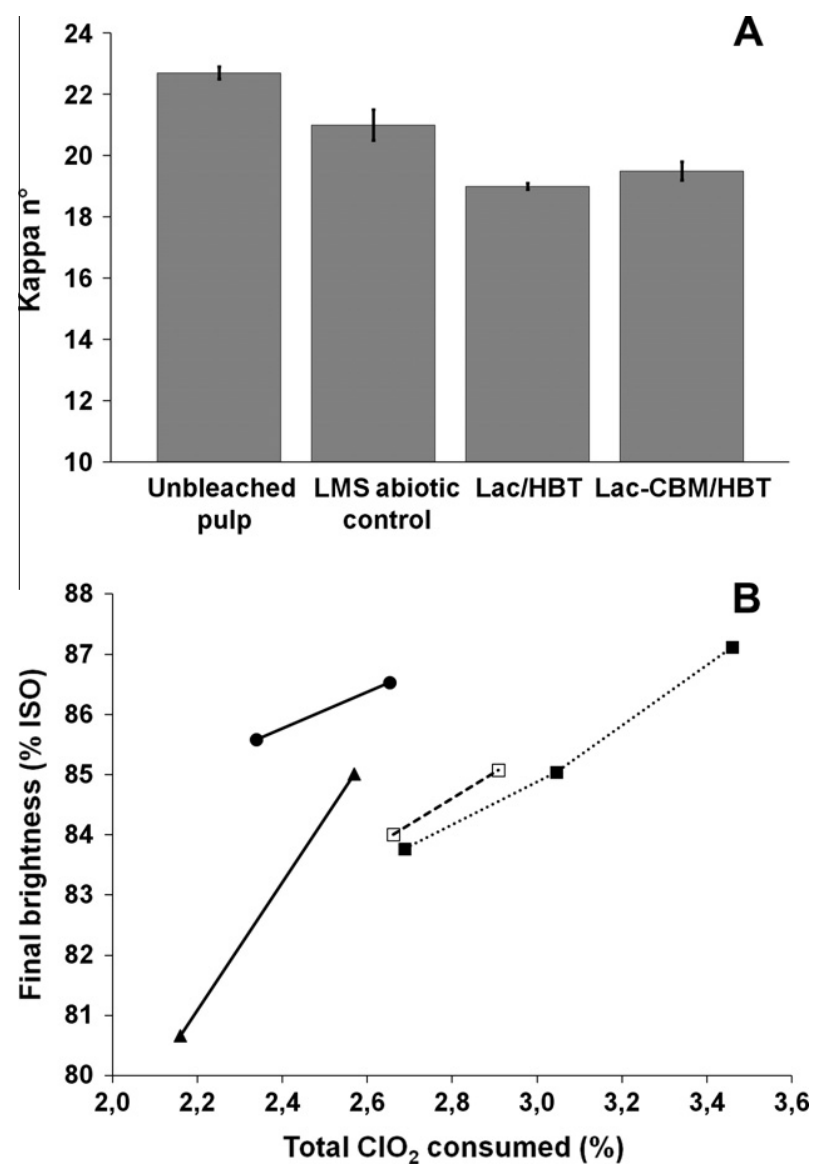

Fig. 1. Effect of laccase/HBT and laccase-CBM/HBT treatments on softwood kraft pulp biobleaching. (A) Effect of the enzymatic treatments on pulp kappa number The pulp was treated with $20 \mathrm{U} / \mathrm{g}$ of laccase (Lac) or $5 \mathrm{U} / \mathrm{g}$ of laccase-CBM (Lac-CBM) in the presence of $1.5 \%$ HBT, under 1 bar $\mathrm{O}_{2}$ pressure and at $5 \%$ pulp consistency. Kappa numbers were measured after an alkaline extraction stage. (B) Final brightness obtained at the end of the DEDED bleaching sequence as function of

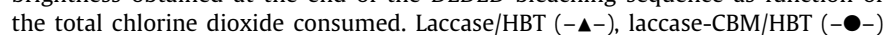
and LMS abiotic treatments (- $\square-)$ were followed by an alkaline extraction stage and a DEDED bleaching sequence. Initial pulp (-口-) was submitted to the same bleaching sequence (ECF bleaching control). Two initial chlorine dioxide charges (kappa factors of 0.18 and 0.21 ) were applied for each pulp. An additional chlorine dioxide charge (kappa factor of 0.24 ) was applied to the ECF bleaching control. 

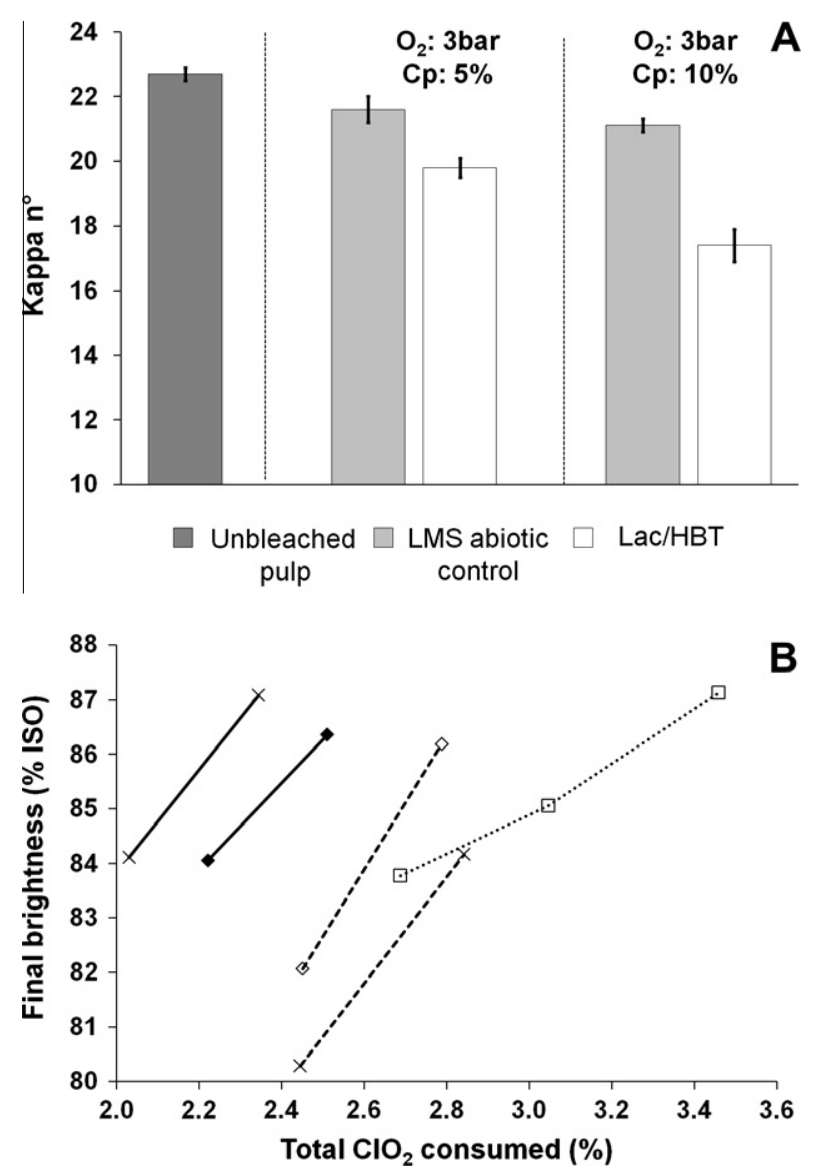

Fig. 2. Impact of an increase in oxygen pressure and pulp consistency on laccase/ HBT softwood kraft pulp biobleaching. (A) Effect of the enzymatic treatments on pulp kappa number. The pulp was treated with $20 \mathrm{U} / \mathrm{g}$ of laccase in the presence of $1.5 \% \mathrm{HBT}$, under 3 bar $\mathrm{O}_{2}$ pressure and at 5 or $10 \%$ pulp consistency. Kappa numbers were measured after an alkaline extraction stage. (B) Final brightness obtained at the end of the DEDED bleaching sequence as function of the total chlorine dioxide consumed. Softwood kraft pulp was submitted to a laccase/HBT treatment, under 3 bar oxygen pressure and $5(--)$ or $10 \%(-\times-)$ pulp consistency. LMS abiotic treatments were performed under 3 bar oxygen pressure and $5(\cdots \diamond \cdots)$ or $10 \%$ $(---\times---)$ pulp consistency. Enzymatic and abiotic treatments were followed by an alkaline extraction stage and a DEDED bleaching sequence. Two initial chlorine dioxide charges (kappa factors of 0.18 and 0.21 ) were applied for each pulp. Results obtained for the ECF bleaching control (kappa factors of $0.18,0.21$ and 0.24 ) are also indicated $(\cdots \mathbf{\square} \cdots)$.

amount of $\mathrm{ClO}_{2}$ consumed by the ECF bleaching control pulp. To reach a final brightness value of 87.1 , i.e. in the same range than the laccase-CBM/HBT treated pulp, an initial kappa factor of 0.24 had to be applied to this control pulp. In this case $\mathrm{ClO}_{2}$ savings of $3.5 \mathrm{~kg} / \mathrm{T}$ of pulp could be calculated for a targeted $86.5 \%$ ISO brightness, for the laccase-CBM/HBT treated pulp.

As bleaching responses of treated pulps, using 1.5\% HBT, were similar to those observed using 3\% HBT (Ravalason et al., 2009), a charge of $1.5 \%$ HBT was used for all the following LMS treatments.

\subsection{Effect of operating conditions on laccase/HBT and laccase-CBM/ HBT treatments}

\subsubsection{Effect of an increase in oxygen pressure and pulp consistency on} laccase/HBT biobleaching

To evaluate the impact of LMS treatment conditions on laccase/ HBT biobleaching of softwood kraft pulp, oxygen pressure was increased from 1 to 3 bar and pulp consistency was increased from $5 \%$ to $10 \%$. Compared to the kappa number value obtained under 1 bar oxygen pressure and 5\% pulp consistency (Fig. 1A), an increase in oxygen pressure from 1 to 3 bar during LMS treatment did not significantly modify pulp kappa number decrease after an alkaline extraction stage (Fig. 2A). However, when both oxygen pressure and pulp consistency were increased ( 3 bar and 10\% consistency), a further decrease in pulp kappa number was observed. Kappa number decrease was about $50 \%$ higher than that measured under the initial LMS treatment conditions. The modification of LMS treatment conditions also led to an improvement in pulp bleachability (Fig. 2B). Indeed, by increasing oxygen pressure at 5\% pulp consistency, higher final brightness values were obtained, for similar values of chlorine dioxide consumption. This result could partially be due to the delignifying effect of oxygen itself, as shown by the bleaching response of abiotic control pulp when $\mathrm{O}_{2}$ pressure was increased. Nevertheless a further bleachability improvement was observed in the presence of laccase and HBT. This could not be expected considering the kappa number values after an alkaline extraction stage. It is likely that pulp physico-chemical modifications occurred and might not be reflected by a simple measurement of kappa number. By increasing pulp consistency at 3 bar oxygen pressure, final brightness was not drastically affected, but a decrease in chlorine dioxide consumption was observed. Hence, the final brightness reached a value of $84.1 \%$ and $87.1 \%$ ISO for an initial kappa factor of 0.18 and 0.21 , respectively. For a targeted $85 \%$ ISO brightness, $\mathrm{ClO}_{2}$ savings of $8.7 \mathrm{~kg} / \mathrm{T}$ of pulp were calculated, as compared to the ECF bleaching control consumption. This value was increased by $4.4 \mathrm{~kg} / \mathrm{T}$ of pulp, considering the savings obtained under 1 bar oxygen pressure and $5 \%$ pulp consistency.

\subsubsection{Comparison of laccase/HBT and laccase-CBM/HBT biobleaching under modified LMS treatment conditions}

The impact of oxygen pressure and pulp consistency was investigated for laccase-CBM/HBT treatment. Both parameters were increased, to reproduce the best conditions observed for the laccase/ HBT treatment. Trials were performed with laccase and laccaseCBM, using 20 and $5 \mathrm{U}$ of enzyme per gram of pulp, respectively, under 3 bar oxygen pressure and at 10\% pulp consistency. A LMS abiotic control was considered under the same conditions. The treated pulps were then submitted to an alkaline extraction stage and to an ECF bleaching using an initial kappa factor of 0.21 . Table 1 shows the kappa number of the treated pulps after an alkaline extraction stage, and the pulp brightness and $\mathrm{ClO}_{2}$ consumed at the end of the $D_{0}$ stage. The results obtained under 1 bar oxygen pressure and at $5 \%$ pulp consistency are also indicated. By applying modified LMS treatment conditions, both laccase/HBT and laccase$\mathrm{CBM} / \mathrm{HBT}$ treatments led to a decrease in pulp kappa number, as well as an increase in pulp brightness at the end of the $\mathrm{D}_{0}$ stage, compared to the ECF bleaching control and LMS abiotic control. However, only the laccase/HBT treatment was improved by the modification of operating conditions, as a $12 \%$ decrease in pulp kappa number, a $19 \%$ decrease in $\mathrm{ClO}_{2}$ consumption and a 5 points increase in brightness were observed. As a comparison, slight modifications of the effect of laccase-CBM/HBT treatment were noted.

It was expected that an increase in oxygen pressure would lead to an increase in pulp delignification in the presence of laccase$\mathrm{CBM} / \mathrm{HBT}$. Indeed, an increase in oxygen pressure can positively affect LMS biobleaching of pulps as it leads to an increase in oxygen solubility, therefore facilitating the oxidation reactions catalyzed by laccase (Moldes and Vidal, 2008; Oudia et al., 2008; Fillat and Roncero, 2009). Concerning the other operating parameter tested here, it could be expected that an increase in pulp consistency would contribute to a better contact between laccase/mediator systems and pulp fibers, leading to the observed increase in biobleaching efficiency. However, if the increase in pulp consistency might have enhanced the efficacy of unbound laccase by increasing the amount of substrate near the enzyme, this result was already obtained by the binding of laccase-CBM to the pulp. As a conse- 
Version définitive du manuscrit publiée dans / Final version of the manuscript published in :

Bioresource Technology (2012), Vol. 121, p. 68-75, DOI: 10.1016/j.biortech.2012.06.077

Journal homepage: http://www.elsevier,com/locate/biortech

Table 1

Comparison of laccase/HBT and laccase-CBM/HBT treatment of softwood kraft pulp.

\begin{tabular}{|c|c|c|c|c|}
\hline \multicolumn{2}{|c|}{ Treatment conditions } & \multirow{2}{*}{$\begin{array}{l}\text { Pulp kappa number }^{\mathrm{a}} \\
22.7 \pm 0.2\end{array}$} & \multirow{2}{*}{$\begin{array}{l}\text { Pulp brightness after } \mathrm{D}_{0}(\% \mathrm{ISO})^{\mathrm{b}} \\
39.2 \pm 0.3\end{array}$} & \multirow{2}{*}{$\begin{array}{l}\mathrm{ClO}_{2} \text { consumed in the } \mathrm{D}_{0} \text { stage }(\%) \\
1.8\end{array}$} \\
\hline Initial pulp & & & & \\
\hline LMS stage: & Abiotic control & $21.0 \pm 0.2$ & $38.8 \pm 0.1$ & 1.7 \\
\hline $\mathrm{PO}_{2}: 1$ bar & Laccase/HBT & $19.0 \pm 0.1$ & $40.4 \pm 0.3$ & 1.6 \\
\hline Cp: $5 \%$ & Laccase-CBM/HBT & $19.5 \pm 0.5$ & $42.7 \pm 0.2$ & 1.6 \\
\hline LMS stage: & Abiotic control & $21.1 \pm 0.2$ & $38.0 \pm 0.3$ & 1.7 \\
\hline $\mathrm{PO}_{2}: 3$ bar & Laccase/HBT & $16.8 \pm 0.4$ & $45.4 \pm 0.1$ & 1.3 \\
\hline Cp: $10 \%$ & Laccase-CBM/HBT & $19.5 \pm 0.1$ & $41.7 \pm 0.1$ & 1.6 \\
\hline
\end{tabular}

a Pulp kappa number was measured after an alkaline extraction stage, except for the initial pulp.

b Kappa factor applied in the $\mathrm{D}_{0}$ stage: 0.21 .

quence, increasing pulp consistency may have no significant impact on laccase-CBM. This should be verified by an independent evaluation of the impact of pulp consistency on laccase-CBM/HBT treatment, and also by increasing the amount of laccase-CBM bound to the pulp fibers.

\subsection{Pulp color after enzymatic treatments and E stage}

Pulp color and brightness were measured after the $3 \mathrm{~h}$ enzymatic stages and after the first alkaline extraction stage. Laccase/ HBT and laccase-CBM/HBT treatments led to a decrease in pulp brightness (Table 2). This effect should be due to the action of enzyme and mediator, as an increase in brightness was observed after the LMS abiotic control treatments. As indicated by the color difference values $(\Delta E *)$, enzymatic and LMS abiotic treatments led to a modification of pulp color, compared to the unbleached kraft pulp. The highest color difference values were observed for the laccase/ HBT treated pulps. Surprisingly, $\Delta E *$ values were higher after the LMS abiotic treatments than after the laccase-CBM/HBT treatment. However, differences in the contribution of each color coordinate could be observed. LMS abiotic treatments led to an increase in lightness, which contributed to a large extent for the color difference observed. Conversely, laccase/HBT and laccase-CBM/HBT treatments led to a decrease in pulp lightness, compared to the LMS abiotic control, as well as a red and yellow shift of pulp color, as shown by the increase in $a *$ and $b *$ coordinates. Red shift was particularly pronounced for both treatments. Increasing oxygen pressure and pulp consistency led to a further increase in color difference for the laccase/HBT treated pulp, mainly due to an increase in redness. As a comparison, no significant differences in pulp color coordinates were observed when these modified treatment conditions were applied to the laccase-CBM/HBT system. Pulp brightness and color were also measured after the first alkaline extraction stage (Table 2). The extraction stage led to an increase in pulp brightness and lightness for the laccase/HBT and laccase-CBM/ HBT treated pulps, whereas the values decreased for the abiotic controls. The alkaline extraction also led to a significant decrease in pulp redness for all LMS-treated pulps, and only to a slight modification of the $b *$ coordinate. The redness values were comparable between laccase/HBT and laccase-CBM/HBT-treated pulps under 1 bar oxygen pressure and 5\% pulp consistency. This value was still high for the laccase/HBT-treated pulp when both oxygen pressure and pulp consistency were increased during LMS treatment. Conversely, no significant modification of the $a *$ coordinate was observed for the laccase-CBM/HBT-treated pulp under modified LMStreatment conditions.

Optical analyses has already been suggested to be a way to study LMS treatments of pulps, as modifications of pulp color were found to be correlated to biobleaching results (Moldes et al., 2010; Moldes and Vidal, 2011). Pulp darkening has previously been observed after LMS treatment of pulps, and was thought to be due to covalent bonds between the mediator and the pulp fibers, or the result of quinone formation during laccase/HBT oxidation of pulp lignin (Chakar and Ragauskas, 2000, 2001; Moldes et al., 2010). Pulp color, and in particular $a *$ coordinate, was also suggested to be correlated with quinone content of chemical pulp (Lachenal et al., 2005). The red shift observed after LMS treatment of pulps could therefore be partially due to quinone formation. It has been shown that quinonoid structures were particularly reactive towards sodium hydroxide and could be removed by an alkaline extraction stage (Zawadzki et al., 1999; Chakar and Ragauskas, 2000), which could lead to the decrease in redness observed for the LMS-treated pulp. Interestingly, the results obtained also suggest that there may be a correlation between the red shift observed after laccase/HBT and laccase-CBM/HBT treatments, and the extent of kappa number decrease after an alkaline extraction stage. In the

Table 2

Impact of laccase/HBT and laccase-CBM/HBT treatment on pulp brightness and color after LMS treatment and an alkaline extraction stage.

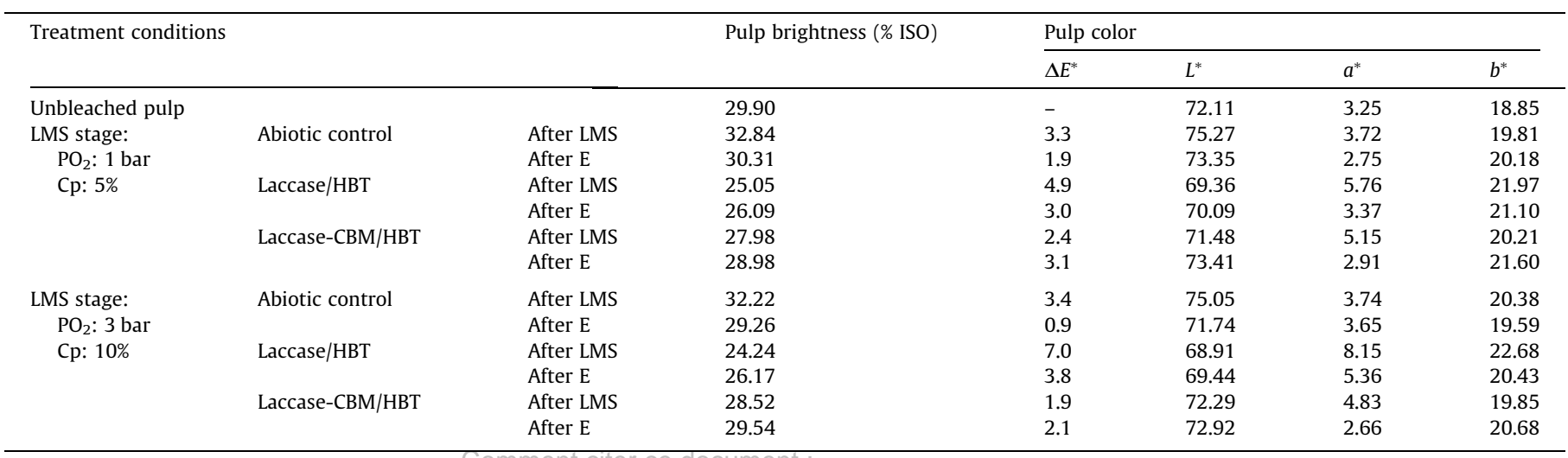


Version définitive du manuscrit publiée dans / Final version of the manuscript published in :

Bioresource Technology (2012), Vol. 121, p. 68-75, DOI: 10.1016/j.biortech.2012.06.077

Journal homepage: http://www.elsevier.com/locate/biortech

same way, pulp optical properties were consistent with the differences in bleachability observed for both systems, under initial and modified LMS treatment conditions. However it must be pointed out that optical properties and decrease in kappa number could not be used to directly compare laccase/HBT and laccase-CBM/ HBT treatments, as indicated by the results obtained under 1 bar oxygen pressure and at 5\% pulp consistency. Indeed, despite a comparable red shift and decrease in kappa number, laccase-CBM/HBT treatment led to a better pulp bleachability than laccase/HBT treatment. In this case, besides LMS-induced lignin oxidation, the action of CBM might also be involved in the differences observed.

\subsection{Physical properties of bleached pulp}

Determination of physical properties is important to evaluate the impact of an enzymatic treatment on pulp quality. Pulp viscosity and average fiber length were measured for the different treatments performed, at the end of the bleaching sequence. Table 3 shows the values obtained for the treatments leading to the same range of brightness values, i.e. 86.5-87\% ISO brightness, as well as the values obtained for the corresponding LMS abiotic controls. To compare laccase/HBT and laccase-CBM/HBT treatments performed under the same conditions, results obtained for the laccase/HBT treatment under 1 bar oxygen pressure and at 5\% pulp consistency were also indicated. All the enzymatic treatments led to a slight decrease in pulp viscosity, as previously shown for laccase/HBT treatment of chemical pulps (Camarero et al., 2004; Ibarra et al., 2006a; Moldes et al., 2010). Laccase/HBT treatment under 3 bar oxygen pressure and at $10 \%$ pulp consistency led to the highest decrease in pulp viscosity. Average fiber length was not significantly modified after the different treatments. Mechanical properties were also evaluated for the different bleached pulps. As shown in Fig. 3A, no significant modification of tear index was observed for the enzyme-treated pulps. As tear index was shown to be mainly dependent on fiber length (Seth and Page, 1988), these results are consistent with the measured average fiber length values. Fig. 3B shows the tensile index measured at the end of the bleaching sequence. Compared to the ECF bleaching control pulp, laccase/ HBT treatments led to a decrease of about $15 \%$ in tensile index. This decrease could partially be explained by the impact of treatment conditions, as shown by the values obtained for the corresponding LMS abiotic controls. These results suggest a weakening of cellulose fibrils involved in interfiber bonding. Conversely, no significant modification was observed for the laccase-CBM/HBT treated pulp. This effect may be due to the action of the CBM. Indeed, it was shown that some fungal CBMs could promote the non-hydrolytic disruption of cellulose fibers (Xiao et al., 2001; Gao et al., 2001). Fungal CBMs have also already been shown to improve pulp properties, and in particular to increase tensile strength of paper sheets (Suurnakki et al., 2000; Pala et al., 2001). It was suggested
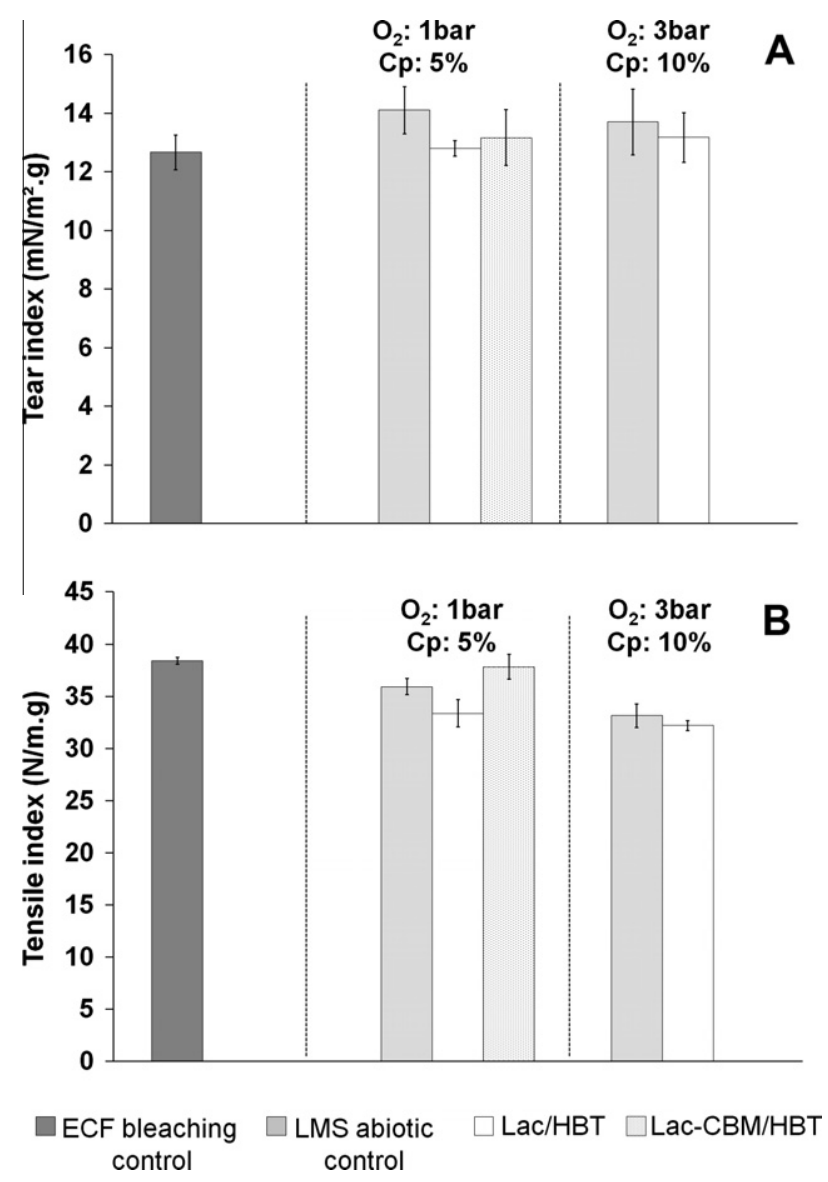

Fig. 3. Tear index (A) and tensile index (B) of LMS-treated pulps and corresponding controls at the end of the bleaching sequence, using an initial kappa factor of 0.24 for the ECF bleaching control and 0.21 for the other pulps.

that this effect could be due to fiber surface and interfacial properties modifications induced by the CBM action (Pala et al., 2001). Fiber surface modifications could therefore have compensated the effect of laccase and HBT as well as treatment conditions.

\subsection{Transmission electron microscopy analysis of softwood kraft pulp fibers}

Localization of laccase and laccase-CBM in softwood kraft pulp fibers taken at the end of the enzymatic treatments was observed after immunogold labeling followed by transmission electron microscopy, using antibodies directed against $P$. cinnabarinus laccase (Fig. S1). Almost no gold particle was detected for laccase-treated pulps (Fig. S1,

Table 3

Properties of the treated pulps at the end of the bleaching sequence.

\begin{tabular}{|c|c|c|c|c|c|}
\hline \multicolumn{2}{|c|}{ Treatment conditions ${ }^{\mathrm{a}}$} & $\begin{array}{l}\text { Final brightness } \\
\text { (\%ISO) }\end{array}$ & $\begin{array}{l}\text { Total } \mathrm{ClO}_{2} \text { consumed } \\
(\%)\end{array}$ & $\begin{array}{l}\text { Bleached pulp viscosity } \\
(\mathrm{ml} / \mathrm{g})\end{array}$ & $\begin{array}{l}\text { Average area-weighted fiber length } \\
(\mathrm{mm})\end{array}$ \\
\hline \multicolumn{2}{|c|}{ ECF bleaching control (KF in $\left.\mathrm{D}_{0}: 0.24\right)$} & $87.1 \pm 0.1$ & 3.5 & $1004 \pm 12$ & $2.09 \pm 0.02$ \\
\hline LMS stage: & Abiotic control (KF in $\left.\mathrm{D}_{0}: 0.21\right)$ & $85.1 \pm 0.1$ & 2.9 & $995 \pm 1$ & $2.00 \pm 0.02$ \\
\hline $\mathrm{PO}_{2}:$ & Laccase/HBT (KF in $\left.\mathrm{D}_{0}: 0.21\right)$ & $85.1 \pm 0.1$ & 2.6 & $974 \pm 3$ & $2.03 \pm 0.01$ \\
\hline $\begin{array}{l}1 \text { bar } \\
\text { Cp: } 5 \%\end{array}$ & $\begin{array}{l}\text { Laccase-CBM/HBT (KF in } \mathrm{D}_{0} \text { : } \\
0.21 \text { ) }\end{array}$ & $86.5 \pm 0.1$ & 2.5 & $946 \pm 4$ & $2.03 \pm 0.04$ \\
\hline LMS stage: & Abiotic control (KF in $\left.\mathrm{D}_{0}: 0.21\right)$ & $84.2 \pm 0.1$ & 2.8 & $982 \pm 4$ & $2.01 \pm 0.05$ \\
\hline $\begin{array}{l}\mathrm{PO}_{2}: \\
3 \text { bar } \\
\text { Cp: } 10 \%\end{array}$ & Laccase/HBT ( KF in $\mathrm{D}_{0}: 0.21$ ) & $87.1 \pm 0.1$ & 2.3 & $929 \pm 6$ & $2.03 \pm 0.04$ \\
\hline
\end{tabular}

a KF: kappa factor. Cp: pulp consistency. 
B) but labeling was significantly increased after laccase-CBM treatment (Fig. S1, C and D), indicating a retention of the enzyme inside the fiber wall as a result of CBM binding. Gold particles were distributed throughout the cell wall demonstrating the penetration of laccase-CBM inside the fibers, with apparently no preferential localization of the enzyme. The ultrastructure of pulp fibers and distribution of lignin were also analyzed after the first alkaline extraction stage, by $\mathrm{KMnO}_{4}$ staining (data not shown). Compared to the unbleached pulp, no significant differences in lignin distribution were observed between the samples. However, as a result of kraft pulping process, general predominant characteristics could be noted despite fiber heterogeneity. Fibers were individualized consequently to lignin dissolution especially from middle lamella, and S1 and S3 layers were detached and lightened due to a superficial penetration of cooking liquor. The opening of the structure induced by the chemical process therefore allowed the enzymes to penetrate and diffuse inside the fiber wall. Even if no clear differences in lignin distribution could be observed between the samples, laccase/HBT and laccaseCBM/HBT treatments clearly led to an increased external microfibrillation of the fibers, as previously observed for pulps treated with lignin-oxidizing enzymes (Sigoillot et al., 2001; Vivekanand et al., 2008).

\subsection{Overall comparison of laccase/HBT and laccase-CBM/HBT systems}

In this study laccase/HBT and laccase-CBM/HBT treatments were integrated into an ECF bleaching sequence. Under 1 bar oxygen pressure and at $5 \%$ pulp consistency, $28 \% \mathrm{ClO}_{2}$ savings were obtained with a laccase-CBM/HBT pre-treatment, for a targeted final brightness of $85 \%$ ISO. With the laccase/HBT system, the same results could be achieved with a higher laccase charge, when both oxygen pressure and pulp consistency were increased. However these modifications also led to a decrease in bleached pulp tensile index. The fusion of a CBM to the $P$. cinnabarinus laccase therefore allowed keeping the same chlorine dioxide savings while still achieving a high brightness and good pulp properties with decreased enzymatic charge. To confirm these promising results, a scaled-up production of laccase-CBM would be needed to validate the process at a pilot-scale, for a potential industrial implementation. Studies are currently being conducted to optimize enzyme production.

\section{Conclusion}

The fusion of a CBM to the $P$. cinnabarinus laccase could improve softwood kraft pulp biobleaching under specific LMS treatment conditions. Laccase/HBT and laccase-CBM/HBT treatments led to a red shift of pulp color, which seemed to be correlated to the extent of kappa number decrease after an alkaline extraction stage. Laccase-CBM/HBT treatment also led to a better preservation of pulp properties, which could be due to surface modifications induced by the CBM action. Microscopic examination of pulp fibers indicated a retention of laccase-CBM inside the pulp fiber, and an increased external microfibrillation after enzymatic treatments.

\section{Acknowledgements}

This study was partly funded by the Biorenew European project (NMP2-CT-2006-026456). H. Ravalason is grateful to the Centre Technique du Papier for her PhD Fellowship.

\section{Appendix A. Supplementary data}

Supplementary data associated with this article can be found, in the online version, at http://dx.doi.org/10.1016/j.biortech.2012.06.077.

\section{References}

Beg, Q.K., Kapoor, M., Mahajan, L., Hoondal, G.S., 2001. Microbial xylanases and their industrial applications: a review. Appl. Microbiol. Biotechnol. 56, 326-338.

Bourbonnais, R., Paice, M.G., 1990. Oxidation of non-phenolic substrates. An expanded role for laccase in lignin biodegradation. FEBS Lett. 267, 99-102.

Camarero, S., García, O., Vidal, T., Colom, J., del Rio, J.C., Gutierrez, A., Gras, J.M. Monje, R., Martinez, M.J., Martinez, A.T., 2004. Efficient bleaching of non-wood high-quality paper pulp using laccase-mediator system. Enzyme Microbiol Technol. 35, 113-120.

Cantarel, B.L., Coutinho, P.M., Rancurel, C., Bernard, T., Lombard, V., Henrissat, B. 2008. The Carbohydrate-Active EnZymes database (CAZy): an expert resource for glycogenomics. Nucleic Acids Res. 37, D233-D238.

Chakar, F.S., Ragauskas, A.J., 2000. The kismet of residual lignin during LMS delignification of high-kappa kraft pulps. Holzforschung 54, 647-653.

Chakar, F.S., Ragauskas, A.J., 2001. Formation of quinonoid structures in laccasemediator reactions. In: Argyropoulos, D.A. (Ed.), Oxidative Delignification Chemistry - Fundamental and Catalysis, ACS Symposium Series, vol. 785. American Chemical Society, Washington, DC, pp. 444-455.

Fatehi, P., Malinen, R.O., Ni, Y., 2009. Bleachability of pulps produced from different kraft pulping methods: a laboratory study. Pulp Pap. Can. 110, 33-38.

Fillat, U., Roncero, M.B., 2009. Biobleaching of high quality pulps with laccase mediator system: influence of treatment time and oxygen supply. Biochem. Eng. J. 44, 193-198.

Gao, P.J., Chen, G.J., Wang, T.H., Zhang, Y.S., Liu, J., 2001. Non-hydrolytic disruption of crystalline structure of cellulose by cellulose binding domain and linker sequence of cellobiohydrolase I from Penicillium janthinellum. Acta Biochim. Biophys. Sin. 33, 13-18.

Herpoël, I., Jeller, H., Fang, G., Petit-Conil, M., Bourbonnais, R., Robert, J.L., Asther, M., Sigoillot, J.C., 2002. Efficient enzymatic delignification of wheat straw pulp by a sequential xylanase-laccase mediator treatment. J. Pulp Pap. Sci. 28, 67-71.

Herpoël, I., Moukha, S., Lesage-Meessen, L., Sigoillot, J., Asther, M., 2000. Selection of Pycnoporus cinnabarinus strains for laccase production. FEMS Microbiol. Lett 183, 301-306.

Ibarra, D., Camarero, S., Romero, J., Martínez, M.J., Martínez, A.T., 2006a. Integrating laccase-mediator treatment into an industrial type sequence for totally chlorine free bleaching of eucalypt kraft pulp. J. Chem. Technol. Biotechnol. 40, 34163422.

Ibarra, D., Romero, J., Martínez, M.J., Martínez, A.T., Camarero, S., 2006b. Exploring the enzymatic parameters for optimal delignification of eucalypt pulp by laccase-mediator. Enzyme Microbiol. Technol. 39, 1319-1327.

Kerr, A.J., Goring, D.A.I., 1975. The ultrastructural arrangement of the wood cell wall. Cellulose Chem. Technol. 9, 563-573.

Lachenal, D., Chirat, C., Benattar, N., Hamzeh, Y., Marlin, N., Mateo, C., Brochier, B. 2005. Influence of pulp color on bleachability. Ways to improve the bleaching response of alkaline pulps. International Pulp Bleaching Conference, Stockholm, 14-16 June 2005, pp. 181-187.

Moldes, D., Vidal, T., 2008. Laccase-HBT bleaching of eucalyptus kraft pulp: influence of the operating conditions. Bioresour. Technol. 99, 8565-8570.

Moldes, D., Cadena, E.M., Vidal, T., 2010. Biobleaching of eucalypt kraft pulp with a two laccase-mediator stages sequence. Bioresour. Technol. 101, 6924-6929.

Moldes, D., Vidal, T., 2011. Reutilization of effluents from laccase-mediator treatments of kraft pulp for biobleaching. Bioresour. Technol. 102, 3603-3606.

Muna, A., Sreekrishnan, T.R., 2001. Aquatic toxicity from pulp and paper mill effluents: a review. Adv. Environ. Res. 5, 175-196.

Ohno, Y., 2000. CIE fundamentals for color measurement. In: Proceedings of the IS\&T NIP16 conference on digital printing technologies, Vancouver, Canada, pp. 540-545.

Oudia, A., Queiroz, J., Simões, R., 2008. The influence of operating parameters on the biodelignification of Eucalyptus globulus kraft pulps in a laccase-violuric acid system. Appl. Biochem. Biotechnol. 149, 23-32.

Pala, H., Lemos, M.A., Mota, M., Gama, F.M., 2001. Enzymatic upgrade of old paperboard containers. Enzyme Microbiol. Technol. 29, 274-279.

Ravalason, H., Herpoël-Gimbert, I., Record, E., Bertaud, F., Grisel, S., de Weert, S., van den Hondel, C.A.M.J.J., Asther, M., Petit-Conil, M., Sigoillot, J.C., 2009. Fusion of a family 1 carbohydrate binding module of Aspergillus niger to the Pycnoporus cinnabarinus laccase for efficient softwood kraft pulp biobleaching. J. Biotechnol. 142, 220-226.

Record, E., Punt, P.J., Chamkha, M., Labat, M., van Den Hondel, C.A., Asther, M., 2002. Expression of the Pycnoporus cinnabarinus laccase gene in Aspergillus niger and characterization of the recombinant enzyme. Eur. J. Biochem. 269, 602-609.

Ruel, K., Faix, O., Joseleau, J.P., 1994. New immunogold probes for studying the distribution of the different lignin types during plant cell wall biogenesis. J. Trace Microprobe Tech. 12, 247-265.

Seth, R.S., Page, D.H., 1988. Fiber properties and tearing resistance. Tappi J. 71, 103 107.

Sigoillot, C., Record, E., Belle, V., Robert, J.L., Levasseur, A., Punt, P.J., van den Hondel, C.A., Fournel, A., Sigoillot, J.C., Asther, M., 2004. Natural and recombinant fungal 
Version définitive du manuscrit publiée dans / Final version of the manuscript published in :

Bioresource Technology (2012), Vol. 121, p. 68-75, DOI: 10.1016/j.biortech.2012.06.077

Journal homepage: http://www.elsevier.com/locate/biortech

laccases for paper pulp bleaching. Appl. Microbiol. Biotechnol. 64, 346-352.

Sigoillot, J.C., Petit-Conil, M., Herpoël, I., Joseleau, J.P., Ruel, K., Kurek, B., de Choudens, C., Asther, M., 2001. Energy saving with fungal enzymatic treatment of industrial poplar alkaline peroxide pulps. Enzyme Microbiol. Technol. 29, 160-165.

Suurnakki, A., Tenkanen, M., Siikaaho, M., Niku-Paavola, M.L., Viikari, L., Buchert, J., 2000. Trichoderma reesei cellulases and their core domains in the hydrolysis and modification of chemical pulp. Cellulose 7, 189-209.

Vivekanand, V., Dwivedi, P., Sharma, A., Sabharwal, N., Singh, R.P., 2008. Enhanced delignification of mixed wood pulp by Aspergillus fumigatus laccase mediator system. World J. Microbiol. Biotechnol. 24, 2799-2804.
Xiao, Z., Gao, P., Qu, Y., Wang, T., 2001. Cellulose-binding domain of endoglucanase III from Trichoderma reesei disrupting the structure of cellulose. Biotechnol. Lett. 23, 711-715.

Zawadzki, M., Runge, T., Ragauskas, A.J., 1999. Investigation of ortho- and paraquinone chromophores in alkaline extraction stage residual lignins. In: Glasser W., Northey, R., Schultz, T. (Eds.), Lignin: Historical, Biological, and Materials Perspectives, ACS Symposium Series, vol. 742. American Chemical Society, Washington, DC, pp. 505-519. 